\title{
Nearshore Bathymetry Estimation Using Video Coastal Monitoring System
}

\author{
Muhammad Zikra ${ }^{1}$
}

\begin{abstract}
The invention of new digital technology of images from video camera systems now can provide information of the shoreward propagation of wave using pixel intensity time series that collected at cross-shore array. From this video image of intensity data, we can measure the wave speed (or, equivalent to wave number). Then the local water depth is inferred from linear wave theory dispersion relation equation. This paper describes the cross-spectral correlation approach scheme for investigating wave speed or equivalent wave number from video image data sets. The approach based on a pixel array analysis that utilizes a nonlinear inverse method. The solution is tolerant to noise and other forms of sampling deficiency. The solution includes error predictions that can be used to evaluate sample designs (data gaps) and the signal coherence. The technique was tested using 30 days of hourly data collected at Egmond beach, Netherlands. The result showed that the method have capability to derive wave number prediction from pixel intensity time series to support bathymetry estimation in near shore area through inversion of an appropriate wave dispersion model.
\end{abstract}

Keywords — Video imagery, Wavenumber, Nearshore bathymetry.

\section{INTRODUCTION}

$\mathrm{T}$ he nearshore is a region where several human activities take places, like recreation, fishing, navigation, etc. This area is known as the dynamic zone which characterised by a dynamic interaction between waves and underlying bathymetry. The breaking waves and current induce sediment transport updating the bed level condition. Then, the new update bathymetry provides feedback to the wave field and modifying the wave characteristic and induces more morphology change to the nearshore bathymetry. These bathymetry changes can occur on temporal time scale (hours to decades) and spatial scales (meters to kilometres) with different degree of complexity. Thus, it is important to understanding the coastal process in the nearshore zone.

Good quality bathymetry information is hence required in order to identify correctly the physical processes that are taking place. However, bathymetric data collection by in situ measurement is not easy task. Combination of traditional in situ survey method and advanced techniques such as global position systems and modern ship vehicles are expensive in labour, time and money. Added, in situ survey measurements have limitation on spatial and temporal resolutions.

Recently, the invention of new digital technology of images form video camera systems now can provide and improve the additional capability of automated data collecti-

\footnotetext{
Manuscript received August 11, 2008, Revised December 31, 2008

${ }^{1} \mathrm{M}$. Zikra is with Department of Ocean Engineering, FTK, Institut Teknologi Sepuluh Nopember, Surabaya, INDONESIA.

Email: mzikro@oe.its.ac.id
}

on. The automated data collections have much greater range of time and spatial scales than were previously possible before. This video camera program (Argus system) is first initiated by the Coastal Imaging Lab of Oregon State University, USA in 1980 [1]. Then, the Argus system have been improved and developed continuously for purposes to study of coastal processes in the nearshore environment area [2].

In these video imagery data it is possible to see the interaction of the incident wave field with the bathymetry (i.e. wave shoaling and refraction); hence this information can be used to obtain estimates of bathymetry [3], [4], [5]. The approach for estimating bathymetry is based on wave kinematics utilize the depth dependence of the wave speed (or, equivalently, the wavelength and frequency via $c=f / k$, where $c$ is the wave phase speed, $f$ is the wave frequency and $k$ is the wavenumber $=1 / L$, and $L$ is the wavelength). Overall, this approach requires image sequence (or time series of intensity at discretely sample locations). The underlying methodology to solve this problem has taken on number of different form. These include finding wavenumber estimate from time series of cross-shore array pixel intensities using cross-spectral scheme [6] and determining wave phase speed from coastal video observation system using cross-correlation analysis technique [7] as opposed to the cross-spectral technique developed by Stockdon and Holman [6].

Both methodologies above are designed to extract estimate of wave speed (or, equivalent the wavenumber) component at select frequency from video imagery. Once the wavenumber have been estimated, the data are used to estimate depth via the wave dispersion relationship. However, the wave phase speed estimates at the offshore and onshore ends of the array and at the location of wave breaking are poorly estimated due to observation noise or sampling deficiency. This problem implies to the bathymetry estimation from a wave dispersion equation. Therefore, the objective of this paper is to provide a new method for estimating wavenumber problem based on an array analysis that utilizes a nonlinear inverse method and to solve the bathymetry estimate problem using an inverse model.

\section{METHOD}

\section{A. Field Site}

This research study was investigated with coastal video-based observation from Egmond and Zee, Netherlands. (see figure 1). The site is located at the approximately North-South oriented central Dutch coast, facing the semi-enclosed North Sea. In general, 
the coast consists of a closed coast with dunes, sandy beach and multi-barred beaches which can be characterized as a wave-dominated coast both the wind wave and the tides.

From the wave measurement, the yearly average wave height $\left(H_{m o}\right)$ is about $1.20 \mathrm{~m}$ with the average wave period $\left(T_{m}\right)$ is $5 \mathrm{sec}$. During normal condition, waves approach the coast most often from the Southwest direction. However, the largest storm waves, with $H_{m o}$ greater than $6 \mathrm{~m}$, are incident from Northwest direction. The range of the semi-diurnal tide is, on average, $1.65 \mathrm{~m}$, varying from $1.4 \mathrm{~m}$ at neap tide to about $2.0 \mathrm{~m}$ at spring tide [7].

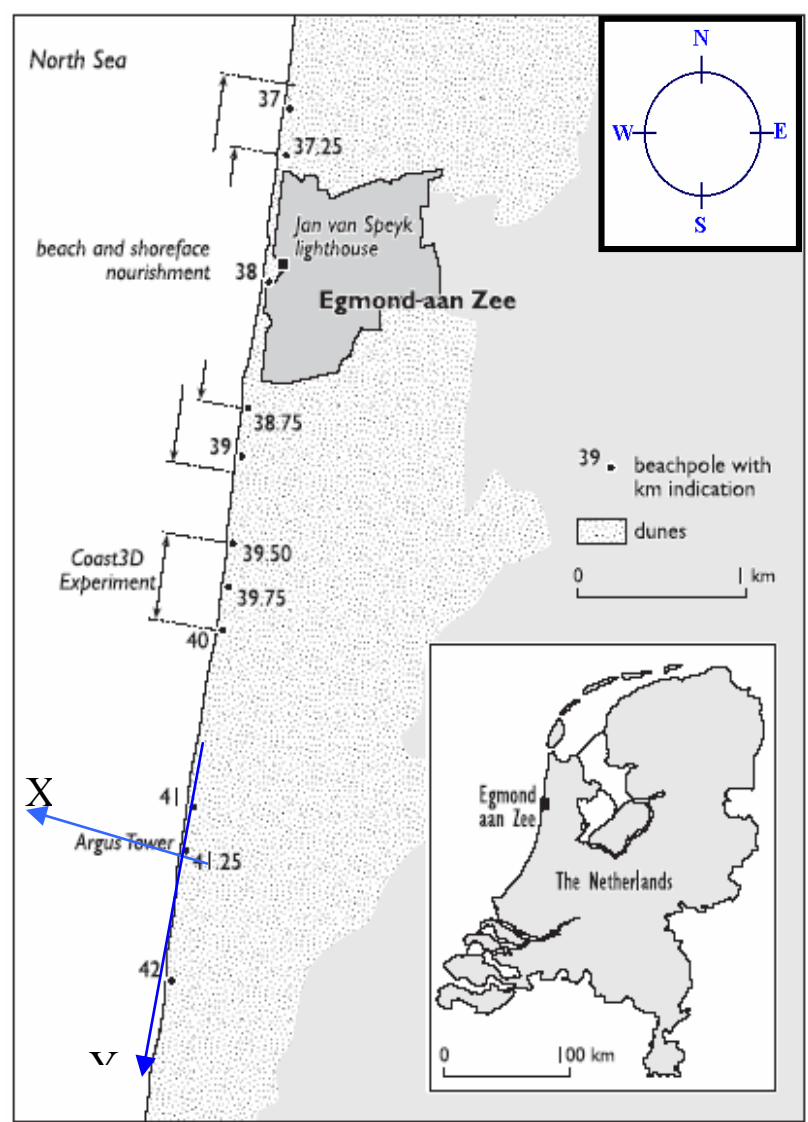

Figure 1 Location site and Argus co-ordinate system at Egmond, Netherlands

[Source: adopted from Aarninkhof and Holman [2]]

\section{B. Argus Video System}

The Argus monitoring station typically consists of five video camera, spanning a $180^{\circ}$ view and full covering about 4 to 6 kilometres of beach area which depends on the elevation and the length of the camera lenses. Unmanned, automated video stations guarantee the collection of video data at sites of scientific interest. The cameras are mounted on a high location along the coast and connected with computer on site which has internet connection to communicate to the outside world. Data sampling is measured usually hourly during daylight and continues during rough weather conditions although any schedule can be specified.

At every Argus site, the orientation of the $\mathrm{x}$-axis is shore normal (cross-shore direction), with the positive $\mathrm{x}$-axis pointing in seaward direction. The $\mathrm{y}$-axis (alongshore) is directed perpendicular to the x-axis, such that the co-ordinate system thus obtained is positive in mathematical sense (Figure 1). The latter means that the rotation from the $\mathrm{x}$-axis towards the $\mathrm{y}$ axis indicates the counter-clockwise or positive turning direction. The vertical reference level $(z=0)$ is generally set to match the mean tidal level (in the Netherlands known as NAP) and all Argus processing is performed in the GMT time frame.

\section{Sampling Design Data}

In this research, data collected at Egmond station in Egmond aan Zee site is tested against non-linear inverse method to extract wave number estimate from time pixel intensities. The new hourly video datasets are collected using three (camera 1, 2 and 3) of five cameras mounted at Delft Hydraulics laboratory facility at Egmond tower station from 19 January until 19 February 2008. The six cross shore arrays pixel sampling was designed to extend $500 \mathrm{~m}$ to offshore direction from the shoreline which contains 101 pixels. In the alongshore direction, 10 lines array are spaced every $25 \mathrm{~m}$ which each line consist of 51 pixels as shown on Figure 2 and Figure 3

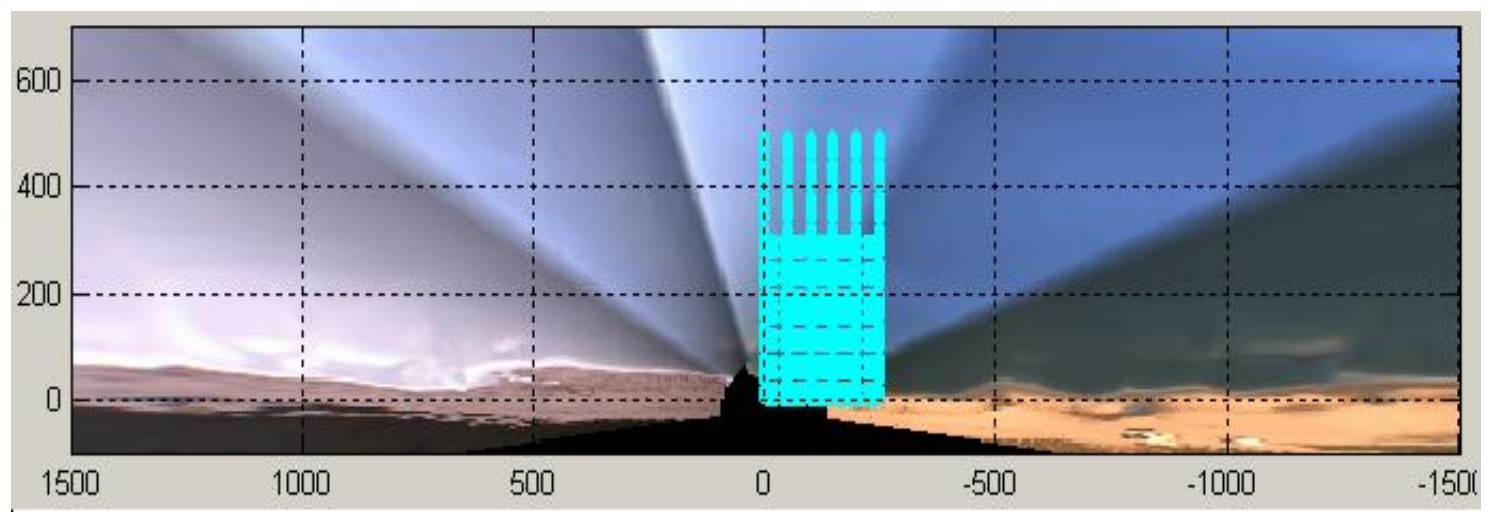

Figure 2. Plan view of study area with pixel array design at Egmond station. The green dots represent bathy array design to create timestack data 


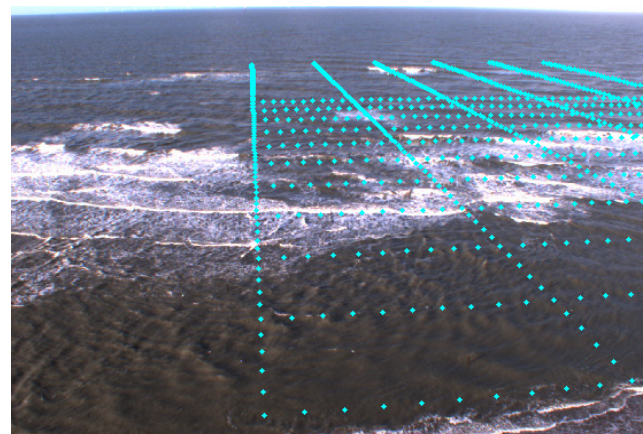

camera 3

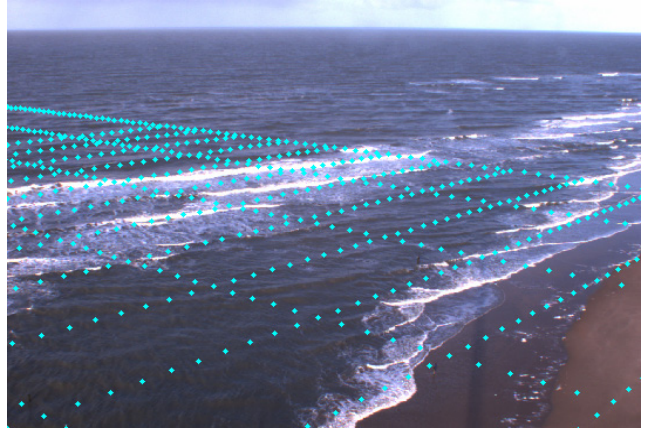

camera 2
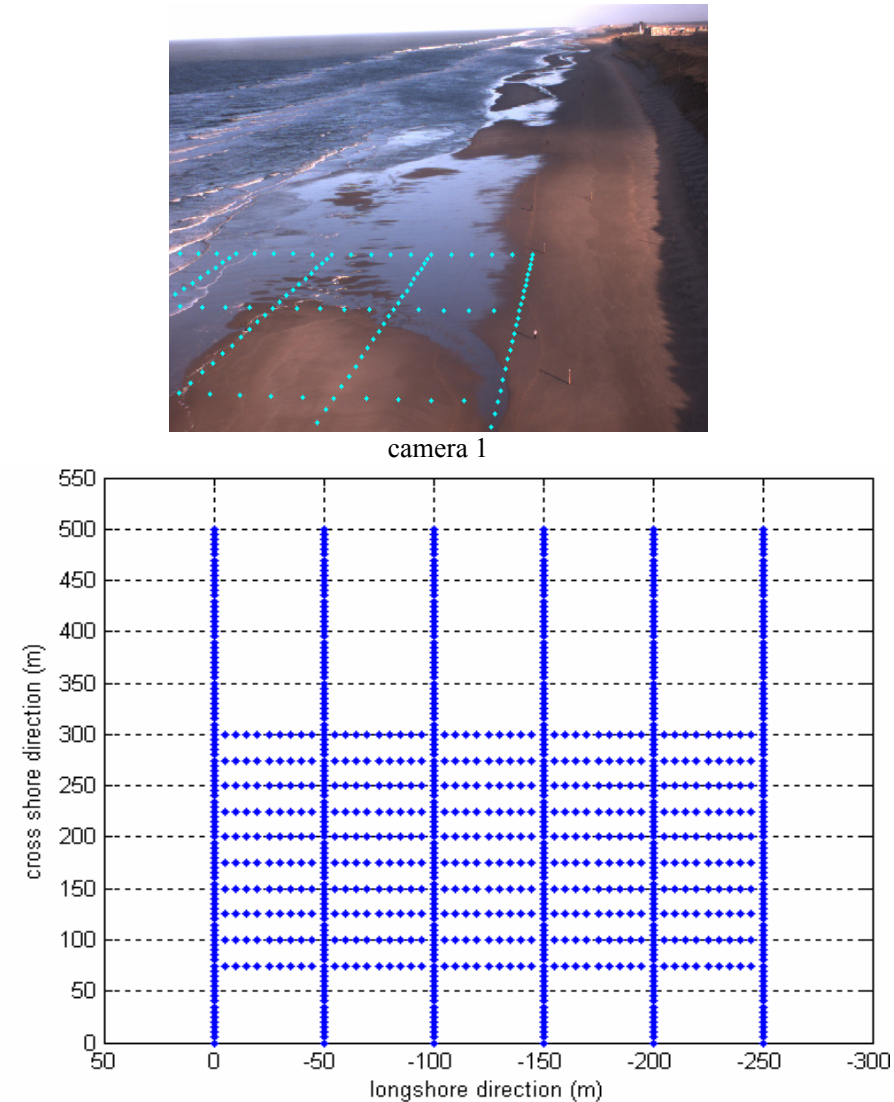

Figure 3. Pixel arrays for the Egmond station experiment. The array pixel design covers the field of view from camera 3, 2 and 1 . The bottom figure is a map view of full extent of the array cover cross shore array and alongshore array.

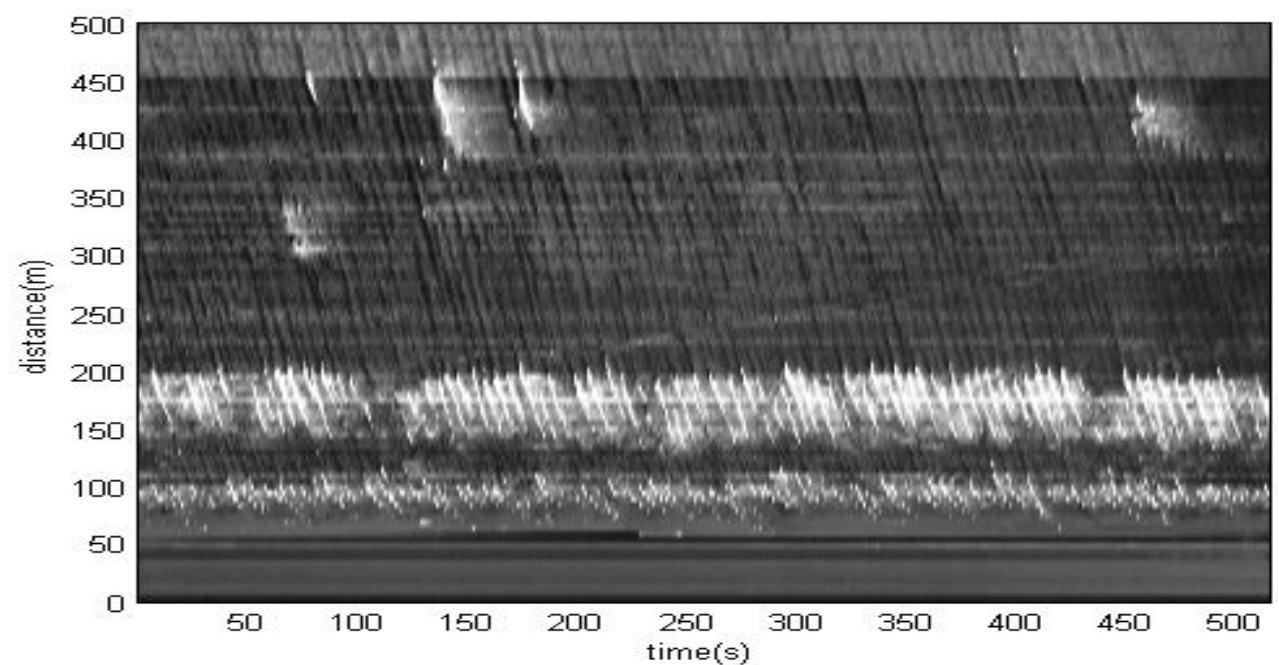

Figure 4. Intensity timestack on January 22, 2008 at 10.15 GMT along cross-shore array $\mathrm{x}=250 \mathrm{~m}$. Bright regions generally indicate wave breaking over shallow regions which start at $150 \mathrm{~m}$ from shoreline. The slope of the wave traces can be used to calculate the aproximate speed of the shoreward progression of waves. 
Based on geometry of the image, the list of sampling location $(x i, y i, z i)$ was converted to a corresponding list of pixel coordinates $(\mathrm{Ui}, \mathrm{Vi})$ [3]. Timestacks of pixel intensity were then collected hourly at each point in the array at rate of $2 \mathrm{~Hz}$ for 17 minute which can be expressed as $I(x i, y i, t)$, where $x i, y i$ is the spatial coordinate of the $i^{\text {th }}$ image pixel, and $t$ are discrete sampling times. At frequencies of interests, we wish to characterize the spatial variation of the wave field, including change in wavelength and direction. This information can then be used to estimate water depth via a wave dispersion relationship. An example of time series of pixel intensities (timestacks) figure at $\mathrm{y}=-250 \mathrm{~m}$ are presented on Figure 3.

\section{Wave number Nonlinear Inverse Method}

In this research, the estimation of wave speed, $c$ (or, equivalent to $k$ ) is determined by using nonlinear inversion method related to the cross-spectral correlation as proposed by Plant et al [8]. We assume that time delay information is available from the spatially separated pixels such that

$$
I\left(x_{i,} y_{i}, t\right)=I\left(x_{j}, y_{j}, t+\Delta t_{i, j, n}\right)
$$

In one spatial dimension, time delay equation can be expressed by equation [9]

$$
\begin{aligned}
\Delta t_{i, j, n} & =\int_{x i}^{x j} \frac{\cos \left(\alpha_{n}[x]\right)}{c_{n}[x]} d x \\
& =\int_{x i}^{x j} \frac{\left.\cos \left(\alpha_{n} \mid x\right]\right) k_{n}[x]}{f_{n}} d_{x}
\end{aligned}
$$

where $\alpha_{n}$ is the direction of the $n^{\text {th }}$ wave component and $c_{n}$ is the celerity of the wave component. This equation is the basis for any tomographic analysis applied to physical properties of the earth [9], including the speed of wave in the ocean [10]

The wave field can be described in discrete spatial domain, with spacing $\Delta x$, and then the discrete time delay equation become:

$$
\begin{aligned}
\Delta t_{i, j, n} & =\Delta x \sum_{m=1}^{M} D_{i, j, m} \frac{\cos \left(\alpha_{n}\left[x_{m}\right]\right)}{c_{n}\left[x_{m}\right]} \\
& =\Delta x \sum_{m=1}^{M} D_{i, j, m} \frac{\cos \left(\alpha_{n}\left[x_{m}\right]\right)}{f_{n}} k_{n}\left[x_{m}\right]
\end{aligned}
$$

where $D$ is design matrix defined on both the sample domain ( $x i, x j)$, and $x_{m}$ is the estimation of domain and $\alpha$ (wave direction) and $c$ (wave celerity) as unknown model parameters.

To utilize the time delay equation with remotely sensed imagery, one must estimate time lag, $\Delta t$, associated with the propagation of the visible wave signal. The time lag will differ for all sensor pairs. This requires some sort of a search for $\Delta t$ that corresponds to a maximum in the cross correlation function $\left(r_{i j}\right)$ as described by:

$$
r_{i, j}(\Delta t)=W(\Delta t) *\left\langle I\left(x_{i}, t\right) I\left(x_{j}, t+\Delta t\right)\right\rangle
$$

where $W$ is a band-passed filter that is convolved against the cross correlation and the angle bracket indicate an ensemble average over all observation times.

Since it is natural to work with wave processes in the frequency domain, an alternative approach is to apply a discrete Fourier transform to the observation and the time de- lay equation can be described as a phase delay by computing the cross-spectra correlation between two sensors pair:

$$
\begin{aligned}
C_{i, j, f}^{O B S}= & \left\langle\tilde{I}\left(x_{i}, f\right) \tilde{I} *\left(x_{j}, f\right)\right\rangle \\
& =\gamma_{i, j, f} \exp \left\{\sqrt{-1} \Phi_{i, j, f}\right\}
\end{aligned}
$$

where the tilde indicate the Fourier transform, the asterisk indicates complex conjugate, angle bracket indicate ensemble or band averaging, $\gamma$ is the coherence, and $\Phi$ is the phase shift between two sample locations $x_{i}$ and $x_{j}$. Since the phase shift between two sensors is $\Phi_{i, j, f}=f . \Delta t_{i, j, f}$, replace $\Delta t$ with the right hand side of (2) and replace $\Phi$ in (4) to get a the model for cross-spectral correlation equation:

$C_{i, j, f}^{M O D E L}=\exp \left\{2 \pi \Delta x \sqrt{-1} \sum_{m=1}^{M} D_{i, j, m} k_{m, f} \cos \left(\alpha_{m, f}\right)\right\}$

While the time delay equation is linier in the crossshore wave number $\left(k_{m, f} \cos \left(\alpha_{m, f}\right)\right)$, the cross-spectral correlation equation is nonlinear function of wave number. Since the wave number is nonlinearly related to the cross-spectral correlation, a typical nonlinear inversion approach such as Levenberg-Marquardt (LM) [12] can used to minimize the weighted squared difference between successive estimated of the model and the observations:

$\Delta C_{i, j, f}^{\tau}=\left\{\gamma_{i, j, f} C_{i, j, f}^{M O D E L(\tau)}-C_{i, j, f}^{O B S}\right\}$

where, at each iteration $\tau$, the model-observation mismatch is weighted by the observed coherence, $\gamma_{i, j, f}$. In two horizontal dimensions, linearized models for wave numbers on the array domain are solved iteratively by equations:

$k_{f, m}^{\tau+1}=k_{f, m}^{\tau}+\Delta k_{f, m}^{\tau}$

$\Delta k_{f, m}^{\tau}=\left(\left[R^{\tau}\right] R^{\tau}\right)^{-1}\left[R^{\tau}\right]^{T} \Delta C_{i, j, f}^{\tau}$

$R^{\tau}=R_{i, j, m, f}^{\tau}=\gamma_{i, j, f} \sqrt{-1} D_{i, j, m} C_{i, j, f}^{M O D E L}(\tau) \Delta x$

where the model-observation mismatch is ordered as a column vector, with each element corresponding to a particular $i-j$ pair of observation locations. The matrix $R$ describes the sensitivity of the cross-spectral correlation to variation in each wave number in the array (tomograpic) domain. Thus, each column of $R$ corresponds to the elements in the array domain, $x_{m}$ and each row corresponds to an $x i-x j$ spatial separation pair. It is possible to efficiently compute $R$ by evaluating $C$ model $(t)$ at the observation locations. In the case where the predicted wave number updates $\left(\Delta k_{f, m}\right)$ do not coverage, the $L M$ method diagonalizes $R$ such that the minimization method is equivalent to gradient descent search

\section{E. Video Technique for Bathymetry Estimation}

From this video intensity data we can measure the wave number estimate $(k)$. The local water depth is then inferred from linear wave theory dispersion relation equation: 


$$
\sigma^{2}=g k \tan h(k h)
$$

where $g$ is the acceleration of gravity and $h$ is the local water depth [13] and the radial frequency $\sigma$ is defined as $2 \pi f$. From (9) the local water depth at cross-shore position $x$ can be found from

$h(x)=\frac{\tan h^{-1}\left(\frac{\sigma^{2}}{g k(x)}\right)}{k(x)}$

Given a value for $f$ (sample frequencies) and $h$ (a guess at the correct depth), this equation can be solved iteratively for wave number. Again, the LM method is used to solve for the value of $h$ that minimize error between the wave number predicted and that estimated from imagery

\section{RESULT AND DISCUSSION}

Using the pixel array data collected on January 22, 2008, the wave number estimate was computed at a series of frequencies ranging from $0.14 \mathrm{~Hz}$ to $0.20 \mathrm{~Hz}$. It is expected from those frequencies resolution the wave will give strong signal for the analysis of pixel intensity time series. The phase and coherence are obtained for all pairs of pixel for each frequency over entire array are shown in figure 4. From the figure 4 the highest coherence is indicated at frequency of $0.16 \mathrm{~Hz}$. From this frequency $(\mathrm{f}=0.16 \mathrm{~Hz}$ ) is expected that the wave number prediction will resolve accurately and provide robust wave number estimates. Note that the peak wave energy does not necessarily correspond to the peak coherence. In this research, the peak wave period based on measurement was $5.5 \mathrm{sec}$; the wave direction was approach from 340 degree from North direction; and the significant wave height was $2.1 \mathrm{~m}$.

Using the measured bathymetry and the tide level at the time of the image collection, the true wave number was compute for each frequency using linear wave theory. The nonlinear inverse estimation method was applied to the sample cross-spectral correlation at each frequency over entire array. Figure 4 shows the wave number estimation results applied to the highest coherence $(\mathrm{f}=16 \mathrm{~Hz})$. The estimated wave numbers were very accurate and estimated robustly at nearly all locations which indicated by small error prediction. The spatial distribution of the predicted errors reflected the locations having high quality data.

The wave number estimation model based on the crossspectral correlation can be extended to a two dimensional domain. Using a cross-shore resolution of $\Delta x_{m}=20 \mathrm{~m}$ and alongshore resolution of $\Delta y_{m}=10 \mathrm{~m}$ are chosen as input for domain area with smoothing scale of $L_{x}=40 \mathrm{~m}$ and $L_{y}=$ $150 \mathrm{~m}$. Both wave number in cross shore and alongshore are estimated from $75 \mathrm{~m}$ to $500 \mathrm{~m}$ of offshore direction. Figure 6 shows the result of a 2-d domain from timestack on 22 January 2008. It shows that the direction of wave approach was clearly uniform from 300 degree to the North.

While the wave number estimates that the present approach provides are directly useful for characterizing the wave directional distribution and for testing wave distribution relationships, a key motivation for this research is to facilitate robust, remote-sensing based bathymetry estimation. Bathymetry estimation requires solution of yet another inverse problem using a suitably accurate dispersion equation that related wave number to water depth (10).

The result of water depth estimated is shown in figure 7 . The bathymetry estimation by invert all frequency shows a robust estimate in most domains. At wave breaking area $(x=175 \mathrm{~m}-200 \mathrm{~m})$, the bathymetry estimate is less accurate with error predictions are larger. At offshore, the bathymetry predictions are too deep. This is likely due to neglecting the wave direction or alongshore wave number component at seaward $>300 \mathrm{~m}$ (see figure 2).

\section{CONCLUSIONS}

The result indicated that the cross-spectral correlation formulation (nonlinear inverse method) have capability to derive wavenumber estimate from the analysis array of time series of pixel intensities (timestack) from coastal motion imagery. The approach is tolerant to noise and other forms of sampling deficiency. Additionally, the method supports bathymetry estimation through inversion of an appropriate wave dispersion model. The technique shows good skill and robust to improve the accuracy of bathymetry prediction at nearshore area

However, this result does not necessarily mean that the method is providing the correct answer for the wavenumber estimate from coastal motion imagery since we do not know the true answer expect through modelling from the surveyed bathymetry at the time data being collected. But, if we compare to the conventional survey technique the video monitoring system is feature simple logistics that are immune to damage from bad weather and frequency data sample can be extended for long period without additional cost.

\section{ACKNOWLEDGMENT}

The author wishes to thank Prof. Dano Roelvink (UNESCO-IHE Institute for Water Education, Delft) and Dr. Ap van Dongeren (WL/Delft Hydraulics) for their extensive helps, supports and dedicated assistances. The work described here was supported by WL/Delft Hydraulic, Delft, Netherlands. 

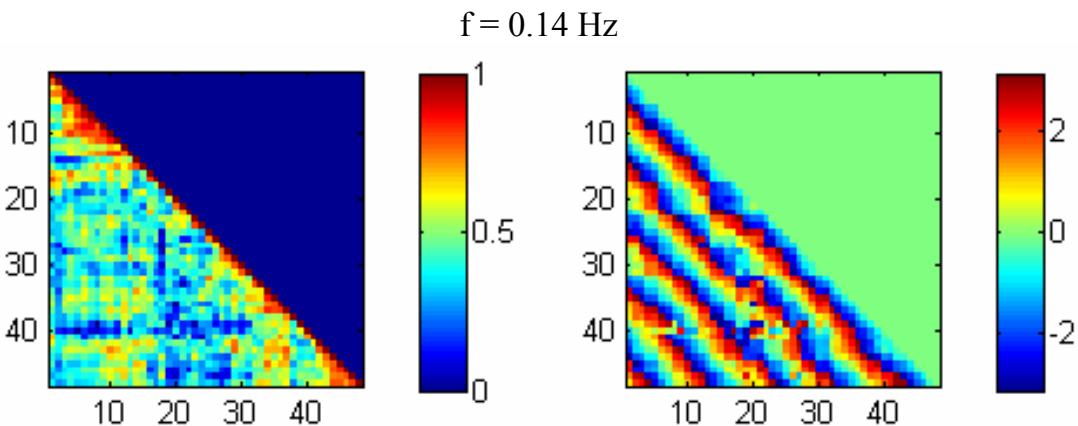

$\mathrm{f}=0.16 \mathrm{~Hz}$
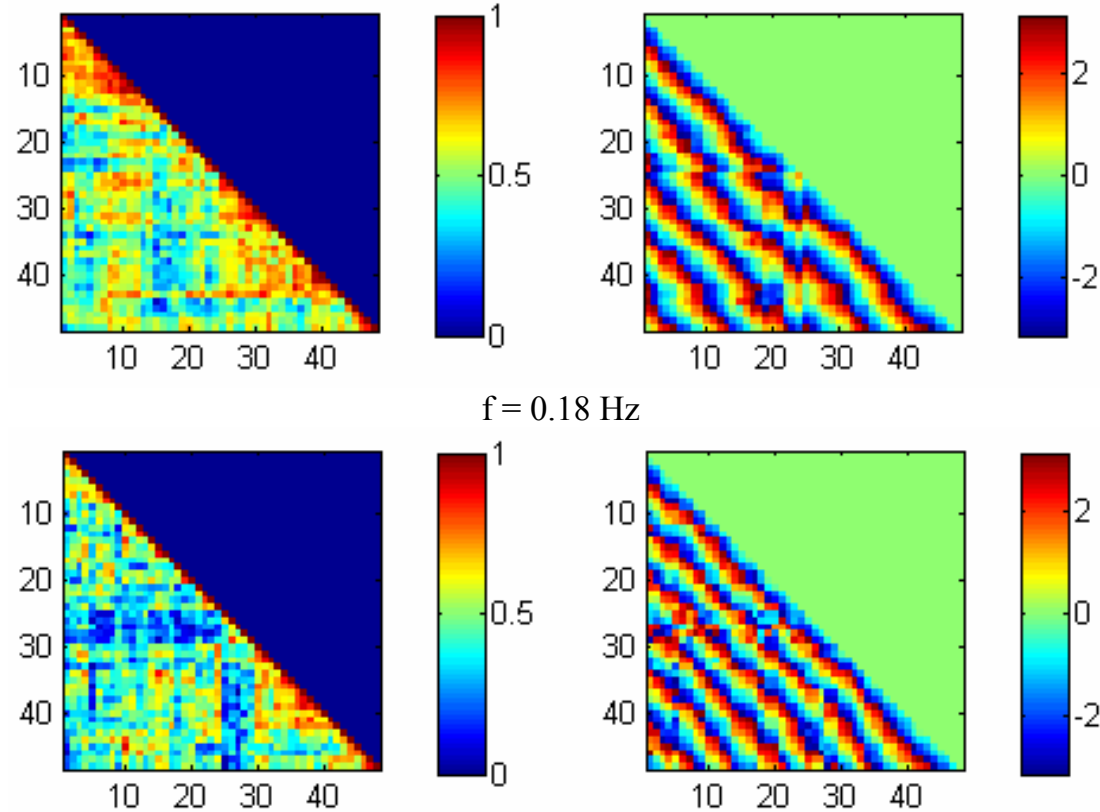

$\mathrm{f}=0.18 \mathrm{~Hz}$
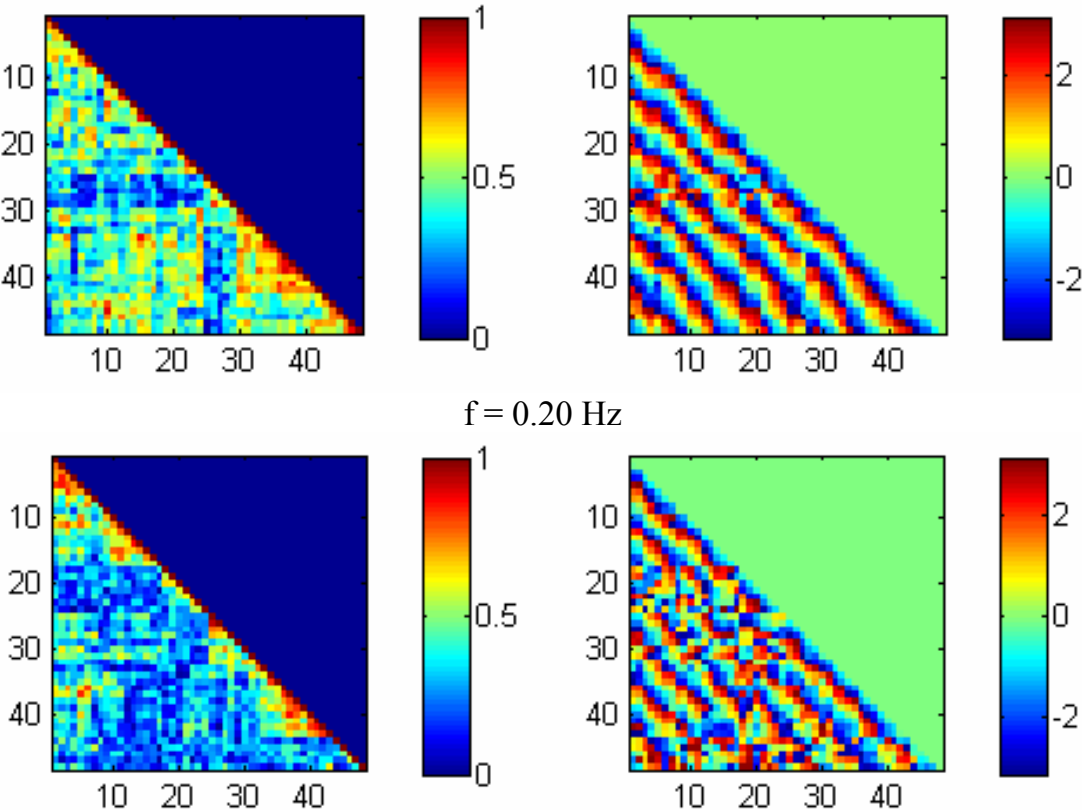

$$
\mathrm{f}=0.20 \mathrm{~Hz}
$$
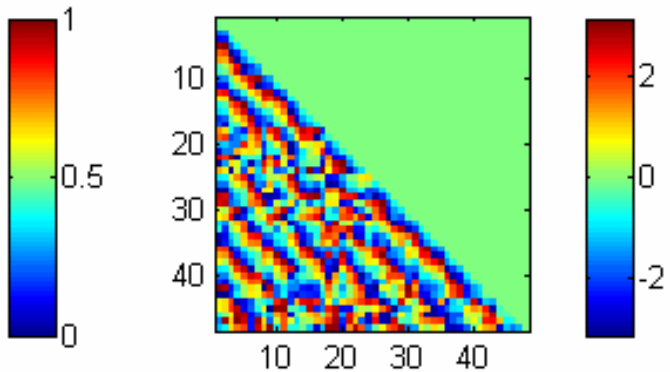

Figure 5. Coherence (left column) and phase (right column) for different frequency from pixel array on January 22, 2008

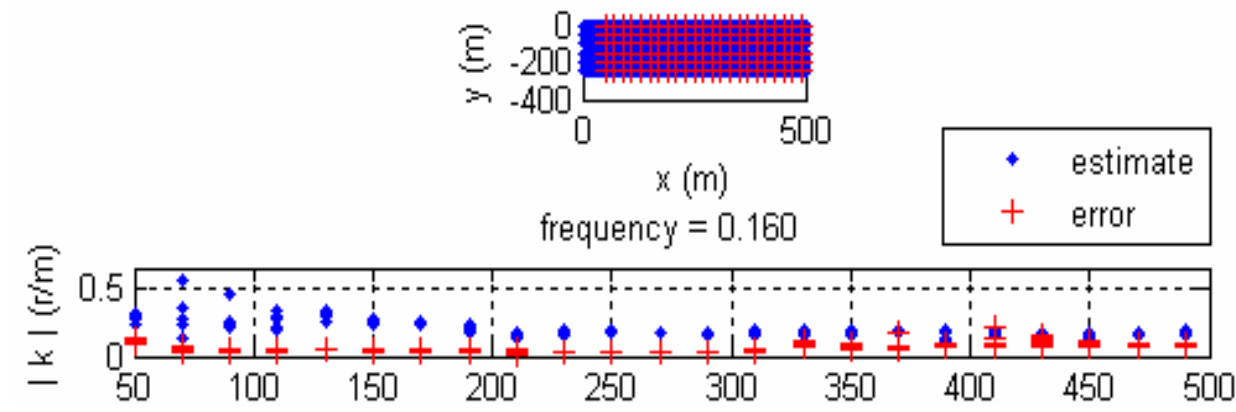

Figure 6. The estimated and the error prediction value of wavenumbers estimate using the nonlinear inverse method at Jan.22_10_15.GMT.2008 


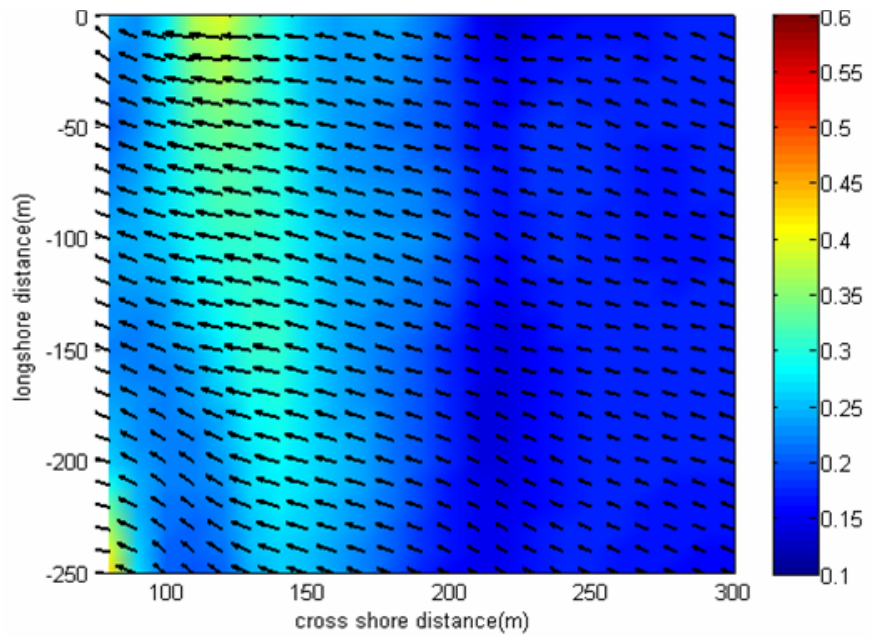

Figure 7. The estimated and the error prediction value of wavenumbers estimate using the nonlinear inverse method at Jan.22_10_15.GMT.2008.
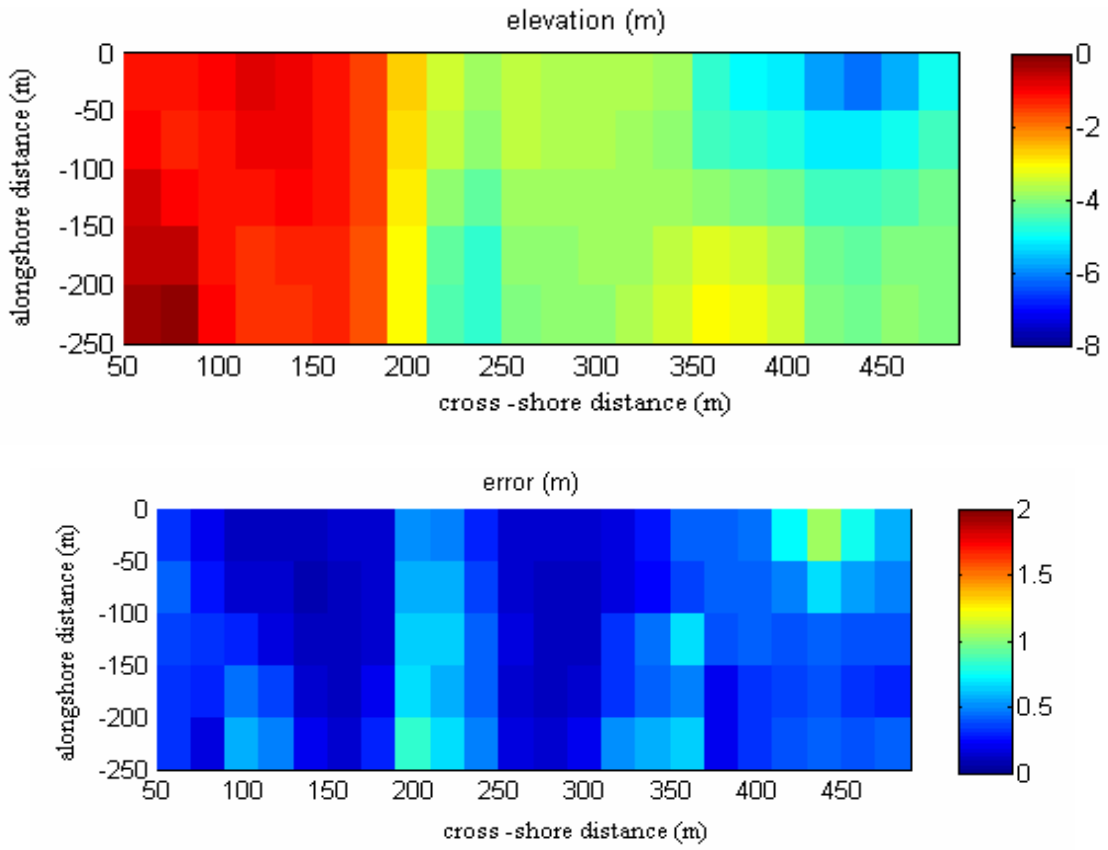

Figure 8. a) Bathymetry estimation map using nonlinear inverse method on Jan.22_10_15_02.GMT.2008, b) Predicted map errors.
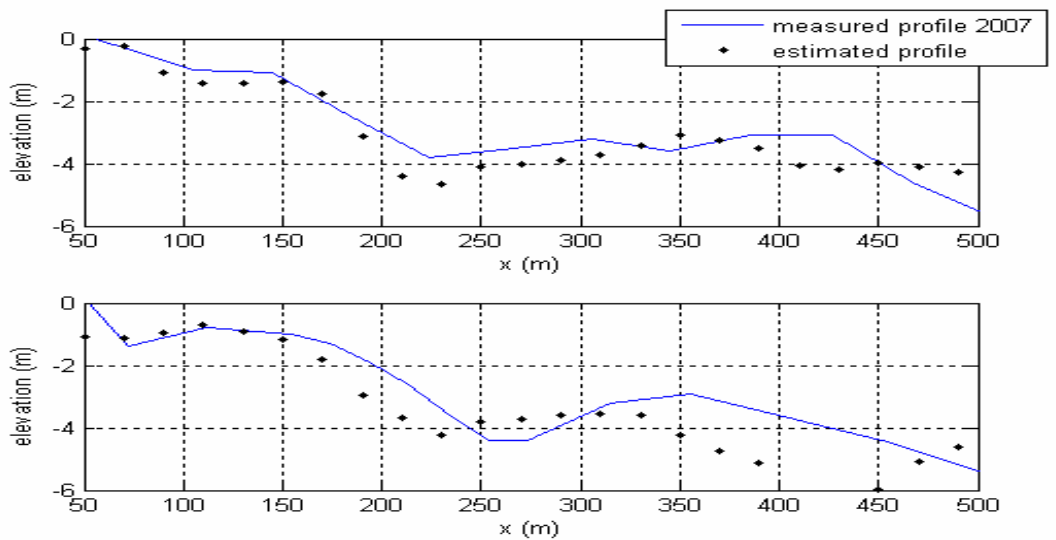

Figure 9. Cross section profile between estimated profile (black dot) and in situ measurement profile (blue line) at alongshore distance, $y=0 \mathrm{~m}$

(Mean Tidal Level elevation, $\mathrm{z}=0 \mathrm{~m}$ )

\section{REFERENCES}

[1] Holman, R.A and J. Stanley, 'The history and technical capabilities of Argus', Coastal Engineering, 54, 477-491. 1991
[2] Aarninkhof, S.G.J. and Holman, R.A., (1999), 'Monitoring the nearshore with video'. Backscatter, vol. 10(2), pp. 8-11. 1999

[3] Holland, K.T, R.A. Holman, T.C. Lipmann, J. Stanley and Plant, 'Practical use of video imagery in nearshore oceanography', IEEE J. Oceanic Engineering, 22(1), 81-92. 1997 
[4] Holman, R.A., T.C. Lippmann, P.V. O'Neill, and K. Hathaway., 'Video estimation of subaerial beach profiles', Marine Geology, 97, 225-231. 1991

[5] Lippmann, T.C., and R.A. Holman., 'Quantification of sand bar morphology: A video technique based on wave dissipation', Journal of Geophysical Research, 94 (C1), 995-1011. 1989

[6] Stockdon, H.F. and Holman, R.A., 'Estimation of wave phase speed and nearshore bathymetry from video imagery', Journal of Geophysical Research 105, pp. 22015-22033.

[7] Zikra, M., Application of wavenumber estimation model using video observation from Egmond aan. 2008

[8] Plant, N.G., K. T. Holman, M. C. Haller., 'Development of wavenumber estimation methods applied to coastal motion imagery', IEEE Transactions on Geoscience and Remote Sensing, 25p. 2007

[9] Bendat, J.S., and A.G. Piersol., Random Data: Analysis \& Measurement Techniques, 566 pp., Wiley Intersci., New York.

[10] Menke, W., Geophysical Data Analysis: Discrete Inverse Theory, Academic Press. 1989.

[11] Munk, W, Worcester, W, and Wunsch, C., Ocean Acoustic Tomography, Cambridge University Press. 1995

[12] Press, W.H, Teukolsky, S.A, Vetterling, W.T, and Flannery, B.P, Numerical Recipes in $C$ : the art of scientific computing, $2^{\text {nd }} e d$, Cambridge University Press. 1992.

[13] Dean, R.G., and R. A. Dalrymple. Water Waves Mechanics for Engineer and Scientist, 353 pp., World Sci., River Edge, N.J. 1991. 